\title{
Common Fixed Point Results for Mappings with Rational Expressions
}

\author{
M. A. Kutbi, ${ }^{1}$ Jamshaid Ahmad, ${ }^{2}$ Nawab Hussain, ${ }^{1}$ and Muhammad Arshad ${ }^{3}$ \\ ${ }^{1}$ Department of Mathematics, King Abdulaziz University, Jeddah, Saudi Arabia \\ ${ }^{2}$ Department of Mathematics, COMSATS Institute of Information Technology, Chak Shahzad, Islamabad 44000, Pakistan \\ ${ }^{3}$ Department of Mathematics, International Islamic University, Sector H-10, Islamabad 44000, Pakistan
}

Correspondence should be addressed to Jamshaid Ahmad; jamshaid_jasim@yahoo.com

Received 2 March 2013; Accepted 14 May 2013

Academic Editor: Irena Rachůnková

Copyright (C) 2013 M. A. Kutbi et al. This is an open access article distributed under the Creative Commons Attribution License, which permits unrestricted use, distribution, and reproduction in any medium, provided the original work is properly cited.

We obtain some common fixed point results for single as well as set valued mappings involving certain rational expressions in complete partial metric spaces. In the process, we generalize various results of the literature. Two examples are also included to illustrate the fact that our results cannot be obtained from the corresponding results in metric spaces.

\section{Introduction and Preliminaries}

In 1994, Matthews [1] introduced the concept of a partial metric space and obtained a Banach type fixed point theorem on a complete partial metric space. Later on, several authors (see, e.g., [1-28]) proved fixed point theorems in partial metric spaces. After the definition of the Partial Hausdorff metric, Aydi et al. [9] proved Banach type fixed point result for set valued mappings in complete partial metric space. Here, we prove some common fixed point results for single as well as set valued mappings involving certain rational expressions in complete partial metric spaces and show by examples that the results proved in this paper cannot be deduced from the corresponding results in metric spaces (see Example 10, Remark 13).

We start with recalling some basic definitions and lemmas on partial metric space. The definition of a partial metric space is given by Matthews (see [1]) as follows.

Definition 1. A partial metric on a nonempty set $X$ is a function $p: X \times X \rightarrow[0, \infty)$ such that for all $x, y, z \in X$ :

$$
\begin{aligned}
& \left(\mathrm{P}_{1}\right) p(x, x)=p(y, y)=p(x, y) \text { if and only if } x=y, \\
& \left(\mathrm{P}_{2}\right) p(x, x) \leq p(x, y), \\
& \left(\mathrm{P}_{3}\right) p(x, y)=p(y, x), \\
& \left(\mathrm{P}_{4}\right) p(x, z) \leq p(x, y)+p(y, z)-p(y, y) .
\end{aligned}
$$

The pair $(X, p)$ is then called a partial metric space.

If $(X, p)$ is a partial metric space, then the function $p^{s}$ : $X \times X \rightarrow \mathbb{R}^{+}$given by $p^{s}(x, y)=2 p(x, y)-p(x, x)-p(y, y)$, $x, y \in X$, is a metric on $X$.

A basic example of a partial metric space is the pair $\left(R^{+}, p\right)$, where $p(x, y)=\max \{x, y\}$ for all $x, y \in R^{+}$.

Lemma 2 (see [1]). Let $(X, p)$ be a partial metric space; then one has the following.

(1) A sequence $\left\{x_{n}\right\}$ in a partial metric space $(X, p)$ converges to a point $x \in X$ if and only if $\lim _{n \rightarrow \infty} p\left(x, x_{n}\right)=p(x, x)$.

(2) A sequence $\left\{x_{n}\right\}$ in a partial metric space $(X, p)$ is called a Cauchy sequence if the $\lim _{n, m \rightarrow \infty} p\left(x_{n}, x_{m}\right)$ exists and is finite.

(3) A partial metric space $(X, p)$ is said to be complete if every Cauchy sequence $\left\{x_{n}\right\}$ in $X$ converges to a point $x \in X$; that is, $p(x, x)=\lim _{n, m \rightarrow \infty} p\left(x_{n}, x_{m}\right)$.

(4) A partial metric space $(X, p)$ is complete if and only if the metric space $\left(X, p^{s}\right)$ is complete. Furthermore, $\lim _{n \rightarrow \infty} p^{s}\left(x_{n}, z\right)=0$ if and only if $p(z, z)=$ $\lim _{n \rightarrow \infty} p\left(x_{n}, z\right)=\lim _{n, m \rightarrow \infty} p\left(x_{n}, x_{m}\right)$. 
Remark 3 (see [1]). Let $(X, p)$ be a partial metric space and let $A$ be a nonempty set in $(X, p)$; then $a \in \bar{A}$ if and only if

$$
p(a, A)=p(a, a),
$$

where $\bar{A}$ denotes the closure of $A$ with respect to the partial metric $p$. Note $A$ is closed in $(X, p)$ if and only if $\bar{A}=A$.

Definition 4 (see [24]). Two families of self-mappings $\left\{T_{i}\right\}_{1}^{m}$ and $\left\{S_{i}\right\}_{1}^{n}$ are said to be pairwise commuting if

(1) $T_{i} T_{j}=T_{j} T_{i}, i, j \in\{1,2, \ldots, m\}$;

(2) $S_{k} S_{l}=S_{l} S_{k}, k, l \in\{1,2, \ldots, n\}$;

(3) $T_{i} S_{k}=S_{k} T_{i}, i \in\{1,2, \ldots, m\}, k \in\{1,2, \ldots, n\}$. [9].

Now we recall the following definitions and results from

Let $C B^{p}(X)$ be the collection of all nonempty, closed, and bounded subsets of $X$ with respect to the partial metric $p$. For $A \in C B^{p}(X)$, we define

$$
p(a, A)=\inf \{p(a, x): x \in A\} .
$$

For $A, B \in C B^{p}(X)$,

$$
\begin{aligned}
& \delta_{p}(A, B)=\sup \{p(a, B): a \in A\}, \\
& \delta_{p}(B, A)=\sup \{p(b, A): b \in B\} .
\end{aligned}
$$

For $A, B \in C B^{p}(X)$,

$$
H_{p}(A, B)=\max \left\{\delta_{p}(A, B), \delta_{p}(B, A)\right\} .
$$

Proposition 5 (see [9]). Let $(X, p)$ be a partial metric space. For any $A, B, C \in C B^{p}(X)$, one has

(i) $\delta_{p}(A, A)=\sup \{p(a, a): a \in A\}$;

(ii) $\delta_{p}(A, A) \leq \delta_{p}(A, B)$;

(iii) $\delta_{p}(A, B)=0$ implies that $A \subseteq B$;

(iv) $\delta_{p}(A, B) \leq \delta_{p}(A, C)+\delta_{p}(C, B)-\inf _{c \in C} p(c, c)$.

Proposition 6 (see [9]). Let $(X, p)$ be a partial metric space. For any $A, B, C \in C B^{p}(X)$, one has

$$
\begin{aligned}
& \left(\mathrm{h}_{1}\right) H_{p}(A, A) \leq H_{p}(A, B) ; \\
& \left(\mathrm{h}_{2}\right) H_{p}(A, B)=H_{p}(B, A) ; \\
& \left(\mathrm{h}_{3}\right) H_{p}(A, B) \leq H_{p}(A, C)+H_{p}(C, B)-\inf _{c \in C} p(c, c) .
\end{aligned}
$$

Lemma 7 (see [9]). Let $A$ and $B$ be nonempty, closed, and bounded subsets of a partial metric space $(X, p)$ and $h>1$. Then, for every $a \in A$, there exists $b \in B$ such that $p(a, b) \leq$ $h H_{p}(A, B)$.

Lemma 8 (see [10]). Let $A$ and $B$ be nonempty, closed, and bounded subsets of a partial metric space $(X, p)$ and $0<h \in \mathbb{R}$. Then, for every $a \in A$, there exists $b \in B$ such that $p(a, b) \leq$ $H_{p}(A, B)+h$.

\section{Results for Single Valued Mappings}

The following result, regarding the existence of the common fixed point of the mappings satisfying a contractive condition on the closed ball, is very useful in the sense that it requires the contractiveness of the mappings only on the closed ball instead of the whole space.

Theorem 9. Let $S, T: X \rightarrow X$ be mappings on a complete $\operatorname{PMS}(X, p)$ and $x_{0}, x, y \in X$ and $r>0$. Suppose that there exist nonnegative reals $\alpha$, $\beta$, and $\gamma$ such that $\alpha+\beta+2 \gamma<1$. If $S$ and $T$ satisfy

$$
\begin{aligned}
p(S x, T y) \leq & \alpha p(x, y) \\
& +\frac{\beta p(x, S x) p(y, T y)+\gamma p(y, S x) p(x, T y)}{1+p(x, y)}
\end{aligned}
$$

for all $x, y \in \overline{B_{p}\left(x_{0}, r\right)}$,

$$
p\left(x_{0}, S x_{0}\right) \leq(1-\lambda)\left(r+p\left(x_{0}, x_{0}\right)\right)
$$

where $\lambda=(\alpha+\gamma) /(1-\beta-\gamma)$. Then there exists a unique point $u \in \overline{B_{p}\left(x_{0}, r\right)}$ such that $u=S u=T u$. Also $p(u, u)=0$.

Proof. Let $x_{0}$ be an arbitrary point in $X$ and define

$$
x_{2 k+1}=S x_{2 k}, \quad x_{2 k+2}=T x_{2 k+1}, \quad \text { where } k=0,1,2, \ldots
$$

We will prove that $x_{n} \in\left(\overline{B\left(x_{0}, r\right)}\right)$ for all $n \in \mathbb{N}$ by mathematical induction. Using inequality (6) and the fact that $\lambda=(\alpha+\gamma) /(1-\beta-\gamma)<1$, we have

$$
p\left(x_{0}, S x_{0}\right) \leq r+p\left(x_{0}, x_{0}\right) .
$$

It implies that $x_{1} \in\left(\overline{B\left(x_{0}, r\right)}\right)$. Let $x_{2}, \ldots, x_{j} \in \overline{B\left(x_{0}, r\right)}$ for some $j \in N$. If $j=2 k+1$, where $k=0,1,2, \ldots(j-1) / 2$, so using inequality (5), we obtain

$$
\begin{aligned}
p\left(x_{2 k+1}, x_{2 k+2}\right) \\
=p\left(S x_{2 k}, T x_{2 k+1}\right) \\
\leq \alpha p\left(x_{2 k}, x_{2 k+1}\right) \\
+\left(\beta p\left(x_{2 k}, S x_{2 k}\right) p\left(x_{2 k+1}, T x_{2 k+1}\right)\right. \\
\left.\quad+\gamma p\left(x_{2 k+1}, S x_{2 k}\right) p\left(x_{2 k}, T x_{2 k+1}\right)\right) \\
\times\left(1+p\left(x_{2 k}, x_{2 k+1}\right)\right)^{-1} \\
\leq \alpha p\left(x_{2 k}, x_{2 k+1}\right) \\
+\left(\beta p\left(x_{2 k}, x_{2 k+1}\right) p\left(x_{2 k+1}, x_{2 k+2}\right)\right. \\
\left.\quad+\gamma p\left(x_{2 k+1}, x_{2 k+1}\right) p\left(x_{2 k}, x_{2 k+2}\right)\right) \\
\times\left(1+p\left(x_{2 k}, x_{2 k+1}\right)\right)^{-1}
\end{aligned}
$$




$$
\begin{aligned}
\leq & \alpha p\left(x_{2 k}, x_{2 k+1}\right) \\
& +\left(\beta p\left(x_{2 k}, x_{2 k+1}\right) p\left(x_{2 k+1}, x_{2 k+2}\right)\right. \\
& \left.+\gamma p\left(x_{2 k}, x_{2 k+1}\right) p\left(x_{2 k}, x_{2 k+2}\right)\right) \\
& \times\left(1+p\left(x_{2 k}, x_{2 k+1}\right)\right)^{-1} \\
\leq & \alpha p\left(x_{2 k}, x_{2 k+1}\right)+\beta p\left(x_{2 k+1}, x_{2 k+2}\right)+\gamma p\left(x_{2 k}, x_{2 k+2}\right),
\end{aligned}
$$

as $1+p\left(x_{2 k}, x_{2 k+1}\right)>p\left(x_{2 k}, x_{2 k+1}\right)$, and so

$$
p\left(x_{2 k+1}, x_{2 k+2}\right) \leq\left(\frac{\alpha+\gamma}{1-\beta-\gamma}\right) p\left(x_{2 k}, x_{2 k+1}\right)
$$

which implies that

$$
p\left(x_{2 k+1}, x_{2 k+2}\right) \leq \lambda p\left(x_{2 k}, x_{2 k+1}\right) \leq \cdots \leq \lambda^{2 k+1} p\left(x_{0}, x_{1}\right) .
$$

If $j=2 k+2$ where $k=0,1,2, \ldots,(j-2) / 2$, one can easily prove that

$$
p\left(x_{2 k+2}, x_{2 k+3}\right) \leq \lambda^{2 k+2} p\left(x_{0}, x_{1}\right) .
$$

Thus from inequality (11) and (12), we have

$$
p\left(x_{j}, x_{j+1}\right) \leq \lambda^{j} p\left(x_{0}, x_{1}\right) \quad \text { for some } j \in N \text {. }
$$

Now

$$
\begin{aligned}
p\left(x_{0}, x_{j+1}\right) \leq & p\left(x_{0}, x_{1}\right)+\cdots+p\left(x_{j}, x_{j+1}\right) \\
& -\left[p\left(x_{1}, x_{1}\right)+\cdots+p\left(x_{j}, x_{j}\right)\right] \\
\leq & p\left(x_{0}, x_{1}\right)+\cdots+\lambda^{j} p\left(x_{0}, x_{1}\right) \\
= & p\left(x_{0}, x_{1}\right)\left[1+\cdots+\lambda^{j-1}+\lambda^{j}\right] \\
\leq & (1-\lambda)\left[r+p\left(x_{0}, x_{0}\right)\right] \frac{\left(1-\lambda^{j+1}\right)}{1-\lambda} \\
\leq & r+p\left(x_{0}, x_{0}\right)
\end{aligned}
$$

gives $x_{j+1} \in \overline{B\left(x_{0}, r\right)}$. Hence $x_{n} \in \overline{B\left(x_{0}, r\right)}$ for all $n \in \mathbb{N}$. One can easily prove that

$$
p\left(x_{n}, x_{n+1}\right) \leq \lambda^{n} p\left(x_{0}, x_{1}\right)
$$

for all $n \in \mathbb{N}$. We now show that $\left\{x_{n}\right\}$ is a Cauchy sequence. Without loss of generality assume that $m>n$. Then, using $\left(13^{*}\right)$ and the triangle inequality for partial metrics $\left(\mathrm{P}_{4}\right)$ we have

$$
\begin{aligned}
p\left(x_{n}, x_{m}\right) \leq & p\left(x_{n}, x_{n+1}\right)+p\left(x_{n+1}, x_{m}\right)-p\left(x_{n+1}, x_{n+1}\right) \\
\leq & p\left(x_{n}, x_{n+1}\right)+p\left(x_{n+1}, x_{m}\right) \\
\leq & p\left(x_{n}, x_{n+1}\right)+p\left(x_{n+1}, x_{n+2}\right)+p\left(x_{n+2}, x_{m}\right) \\
& \quad-p\left(x_{n+2}, x_{n+2}\right) \\
\leq & p\left(x_{n}, x_{n+1}\right)+p\left(x_{n+1}, x_{n+2}\right)+p\left(x_{n+2}, x_{m}\right) .
\end{aligned}
$$

Inductively, we have

$$
\begin{aligned}
0 & \leq p\left(x_{n}, x_{m}\right) \\
& \leq p\left(x_{n}, x_{n+1}\right)+p\left(x_{n+1}, x_{n+2}\right)+\cdots+p\left(x_{m-1}, x_{m}\right) \\
& \leq \lambda^{n} p\left(x_{0}, x_{1}\right)+\lambda^{n+1} p\left(x_{0}, x_{1}\right)+\cdots+\lambda^{m-1} p\left(x_{0}, x_{1}\right) \\
& \leq\left(\lambda^{n}+\lambda^{n+1}+\cdots+\lambda^{m-1}\right) p\left(x_{0}, x_{1}\right) \\
& \leq\left(\frac{\lambda^{n}}{1-\lambda}\right) p\left(x_{0}, x_{1}\right) \\
& \longrightarrow 0 \quad \text { as } n \longrightarrow \infty(\text { since } 0<\lambda<1) .
\end{aligned}
$$

Thus,

$$
\lim _{n \rightarrow+\infty} p\left(x_{n}, x_{m}\right)=0 \text {. }
$$

By the definition of $p^{s}$, we get for any $m \in \mathbb{N}^{*}$,

$$
p^{s}\left(x_{n}, x_{m}\right) \leq 2 p\left(x_{n}, x_{m}\right) \longrightarrow 0 \quad \text { as } n \longrightarrow+\infty .
$$

Hence the sequence $\left\{x_{n}\right\}$ is a Cauchy sequence in $\left(\overline{B\left(x_{0}, r\right)}, p^{s}\right)$. By Lemma 2(4), $\left\{x_{n}\right\}$ is a Cauchy sequence in $\left(\overline{B\left(x_{0}, r\right)}, p\right)$. Therefore there exists a point $u \in \overline{B\left(x_{0}, r\right)}$ with $\lim _{n \rightarrow \infty} x_{n}=u$. Also $\lim _{n \rightarrow \infty} p^{s}\left(x_{n}, u\right)=0$. Again from Lemma 2(4), we have

$$
p(u, u)=\lim _{n \rightarrow+\infty} p\left(x_{n}, u\right)=\lim _{n \rightarrow+\infty} p\left(x_{n}, x_{m}\right)=0 .
$$

By the triangle inequality $\left(\mathrm{P}_{4}\right)$, we have

$$
\begin{aligned}
p(u, S u) \leq & p\left(u, x_{2 n+2}\right)+p\left(x_{2 n+2}, S u\right)-p\left(x_{2 n+2}, x_{2 n+2}\right) \\
\leq & p\left(u, x_{2 n+2}\right)+p\left(T x_{2 n+1}, S u\right) \\
\leq & p\left(u, x_{2 n+2}\right)+\alpha p\left(x_{2 n+1}, u\right) \\
& +\left(\beta p\left(x_{2 n+1}, T x_{2 n+1}\right) p(u, S u)\right. \\
& \left.+\gamma p\left(u, T x_{2 n+1}\right) p\left(x_{2 n+1}, S u\right)\right) \\
& \times\left(1+p\left(x_{2 n+1}, u\right)\right)^{-1} \\
\leq & p\left(u, x_{2 n+2}\right)+\alpha p\left(x_{2 n+1}, u\right) \\
& +\left(\beta p\left(x_{2 n+1}, x_{2 n+2}\right) p(u, S u)\right. \\
& \left.+\gamma p\left(u, x_{2 n+2}\right) p\left(x_{2 n+1}, S u\right)\right) \\
& \times\left(1+p\left(x_{2 n+1}, u\right)\right)^{-1} .
\end{aligned}
$$

Letting $n \rightarrow+\infty$ and using (19), we obtain

$$
p(u, S u)=0 .
$$

By $\left(\mathrm{P}_{1}\right)$, we concluded that $u=S u$. It follows similarly that $u=T u$. To prove the uniqueness of common fixed point, let 
$u^{*} \in \overline{B\left(x_{0}, r\right)}$ be another common fixed point of $S$ and $T$, that, is $u^{*}=S u^{*}=T u^{*}$. Then

$$
\begin{aligned}
p\left(u, u^{*}\right)= & p\left(S u, T u^{*}\right) \\
\leq & \alpha p\left(u, u^{*}\right) \\
& +\frac{\beta p(u, S u) p\left(u^{*}, T u^{*}\right)+\gamma p\left(u^{*}, S u\right) p\left(u, T u^{*}\right)}{1+p\left(u, u^{*}\right)} \\
= & \alpha p\left(u, u^{*}\right)+\frac{\gamma p\left(u^{*}, u\right) p\left(u, u^{*}\right)}{1+p\left(u, u^{*}\right)}
\end{aligned}
$$

so that $p\left(u, u^{*}\right) \leq \alpha p\left(u, u^{*}\right)+\gamma p\left(u, u^{*}\right)$ because $1+p\left(u, u^{*}\right)>$ $p\left(u, u^{*}\right)$. Therefore $p\left(u, u^{*}\right) \leq(\alpha+\gamma) p\left(u, u^{*}\right)$ which is a contradiction so that $u=u^{*}$ (as $\alpha+\gamma<1$ ). Hence $S$ and $T$ have a unique common fixed point in $\overline{B\left(x_{0}, r\right)}$.

Example 10. Let $X=[0,+\infty)$ endowed with the usual partial metric $p$ defined by $p: X \times X \rightarrow \mathbb{R}^{+}$with $p(x, y)=$ $\max \{x, y\}$. Clearly, $(X, p)$ is a partial metric space. Now we define $S, T: X \rightarrow X$ as

$$
\begin{aligned}
& S(x)= \begin{cases}\frac{x}{16} & \text { if } 0 \leq x \leq 1 \\
x-\frac{1}{6} & \text { if } x>1\end{cases} \\
& T(x)= \begin{cases}\frac{5 x}{17} & \text { if } 0 \leq x \leq 1 \\
x-\frac{1}{7} & \text { if } x>1\end{cases}
\end{aligned}
$$

for all $x \in X$. Taking $\alpha=1 / 5, \beta=1 / 6, \gamma=1 / 8, x_{0}=1 / 2$, and $r=1 / 2$, then $\overline{B_{p}\left(x_{0}, r\right)}=[0,1]$. Also, we have $p\left(x_{0}, x_{0}\right)=$ $\max \{1 / 2,1 / 2\}=1 / 2, \lambda=(\alpha+\gamma) /(1-\beta-\gamma)=39 / 85$ with

$$
\begin{gathered}
(1-\lambda)\left(r+p\left(x_{0}, x_{0}\right)\right)=\frac{46}{85}, \\
p\left(x_{0}, S x_{0}\right)=p\left(\frac{1}{2}, \frac{1}{32}\right)=\frac{1}{2}<(1-\lambda)\left(r+p\left(x_{0}, x_{0}\right)\right) .
\end{gathered}
$$

Also if $x, y \in(1,+\infty)$, then

$$
\begin{aligned}
p(S x, T y)= & \max \left\{x-\frac{1}{6}, x-\frac{1}{7}\right\} \geq \frac{1}{5} \max \{x, y\} \\
& +\left(\frac{1}{6} \max \left\{x, x-\frac{1}{6}\right\} \max \left\{y, y-\frac{1}{7}\right\}\right. \\
& \left.\quad+\frac{1}{8} \max \left\{y, x-\frac{1}{6}\right\} \max \left\{x, y-\frac{1}{7}\right\}\right) \\
& \times(1+\max \{x, y\})^{-1} \\
= & \alpha p(x, y) \\
& +\frac{\beta p(x, S x) p(y, T y)+\gamma p(y, S x) p(x, T y)}{1+p(x, y)} .
\end{aligned}
$$

So the contractive condition does not hold on whole of $X$. Now if $x, y \in \overline{B_{p}\left(x_{0}, r\right)}$, then

$$
\begin{aligned}
p(S x, T y)= & \max \left\{\frac{x}{16}, \frac{5 y}{17}\right\} \leq \frac{1}{5} \max \{x, y\} \\
& +\left(\frac{1}{6} \max \left\{x, x-\frac{1}{6}\right\} \max \left\{y, y-\frac{1}{7}\right\}\right. \\
& \left.+\frac{1}{8} \max \left\{y, x-\frac{1}{6}\right\} \max \left\{x, y-\frac{1}{7}\right\}\right) \\
& \times(1+\max \{x, y\})^{-1} .
\end{aligned}
$$

Therefore, all the conditions of Theorem 9 are satisfied. Thus 0 is the common fixed point of $S$ and $T$ and $p(0,0)=0$. Moreover, note that for any metric $d$ on $X$

$$
\begin{aligned}
d(S 1, T 1)= & d\left(\frac{1}{16}, \frac{5}{17}\right)>\frac{1}{5} d(1,1) \\
& +\left(\frac{1}{6} d\left(1, \frac{1}{16}\right) d\left(1, \frac{5}{17}\right)\right. \\
& \left.+\frac{1}{8} d\left(1, \frac{1}{16}\right) d\left(1, \frac{5}{17}\right)\right) \\
& \times(1+d(1,1))^{-1} .
\end{aligned}
$$

Therefore common fixed points of $S$ and $T$ cannot be obtained from a metric fixed point theorem.

Corollary 11. Let $S, T: X \rightarrow X$ be mappings on a complete $P M S(X, p)$. Suppose that there exist nonnegative reals $\alpha, \beta$, and $\gamma$ such that $\alpha+\beta+2 \gamma<1$. If $S$ and T satisfy

$$
\begin{aligned}
p(S x, T y) \leq & \alpha p(x, y) \\
& +\frac{\beta p(x, S x) p(y, T y)+\gamma p(y, S x) p(x, T y)}{1+p(x, y)}
\end{aligned}
$$

for all $x, y \in X$. Then there exists a unique point $u \in X$ such that $u=S u=T u$. Also $p(u, u)=0$. Further $S$ and $T$ have no fixed point other than $u$.

By choosing $\beta=\gamma=0$ in Corollary 11, we get the following corollary.

Corollary 12. Let $S, T: X \rightarrow X$ be a mappings on complete $P M S(X, p)$. If $S$ and $T$ satisfy

$$
p(S x, T y) \leq \alpha p(x, y)
$$

for all $x, y \in X, \alpha<1$ ( $\alpha$ is a nonnegative real). Then $S$ and $T$ have a common fixed point $u \in X$ and $p(u, u)=0$.

Remark 13. If we impose Banach type contractive condition for a pair $S, T: X \rightarrow X$ of mappings on a metric space $(X, d)$; that is, $d(S x, T y) \leq \alpha d(x, y)$ for all $x, y \in X$, and then it follows that $S x=T x$, for all $x \in X$ (i.e., $S$ and $T$ are 
equal). Therefore the above condition fails to find common fixed points of $S$ and $T$. This can be seen as

$$
d(S 1, T 1)=d\left(\left(\frac{1}{16}\right),\left(\frac{5}{17}\right)\right)>\alpha d(1,1)=0 .
$$

However the same condition in partial metric space does not assert that $S=T$. This can be seen as by taking the partial metric same as in Example 10,

$$
p(S 1, T 1)=p\left(\left(\frac{1}{16}\right),\left(\frac{5}{17}\right)\right)=\frac{5}{17} \leq \alpha p(1,1)=\alpha(1) .
$$

for any $\alpha \geq 1 / 3$. Hence Corollary 12 cannot be obtained from a metric fixed point theorem.

Remark 14. By equating $\alpha, \beta, \gamma$ to 0 in all possible combinations, one can derive a host of corollaries which include Matthews theorem for mappings defined on a complete partial metric space.

By taking $S=T$ in the Theorem 9, we get the following corollary.

Corollary 15. Let $T: X \rightarrow X$ be a mapping on a complete PMS $(X, p)$ and $x_{0}, x, y \in X$ and $r>0$. Suppose that there exist nonnegative reals $\alpha, \beta$, and $\gamma$ such that $\alpha+\beta+2 \gamma<1$. If T satisfies

$$
\begin{aligned}
p(T x, T y) \leq & \alpha p(x, y) \\
& +\frac{\beta p(x, T x) p(y, T y)+\gamma p(y, T x) p(x, T y)}{1+p(x, y)}
\end{aligned}
$$

for all $x, y \in \overline{B_{p}\left(x_{0}, r\right)}$,

$$
p\left(x_{0}, T x_{0}\right) \leq(1-\lambda)\left(r+p\left(x_{0}, x_{0}\right)\right),
$$

where $\lambda=(\alpha+\gamma) /(1-\beta-\gamma)$. Then there exists a unique point $u \in \overline{B_{p}\left(x_{0}, r\right)}$ such that $u=T u$. Also $p(u, u)=0$. Further $T$ has no fixed point other than $u$.

By taking $S=T$ in Corollary 11, we get the following corollary.

Corollary 16. Let $T: X \rightarrow X$ be a mapping on a complete PMS $(X, p)$. Suppose that there exist nonnegative reals $\alpha, \beta$, and $\gamma$ such that $\alpha+\beta+2 \gamma<1$. If T satisfies

$$
\begin{aligned}
p(T x, T y) \leq & \alpha p(x, y) \\
& +\frac{\beta p(x, T x) p(y, T y)+\gamma p(y, T x) p(x, T y)}{1+p(x, y)}
\end{aligned}
$$

for all $x, y \in X$. Then there exists a unique point $u \in X$ such that $u=T u$. Also $p(u, u)=0$. Further $T$ has no fixed point other than $u$.
Now we give an example in favour of Corollary 16.

Example 17. Let $X=[0,4]$ endowed with the usual partial metric $p$ defined by $p(x, y)=\max \{x, y\}$. Clearly, $(X, p)$ is a complete partial metric space. Now we define $F: X \rightarrow X$ as follows:

$$
F(x)= \begin{cases}\frac{x}{3} & \text { if } 0 \leq x<2 \\ \frac{x}{1+x} & \text { if } 2 \leq x \leq 4\end{cases}
$$

for all $x \in X$. Now, let $y \leq x$. If $x \in[0,2)$ (and so $y \in[0,2)$ ). Then $p(F x, F y)=x / 3, p(x, y)=x, p(x, F x)=x, p(y, F y)=$ $y, p(y, F x)=x / 3, p(x, F y)=x$. Taking $\alpha=1 / 3, \beta=1 / 15$, $\gamma=2 / 15$, we can prove that all the conditions of Corollary 16 are satisfied. Now if $x \in[2,4]$, then $p(F x, F y)=x /(1+x)$, $p(x, y)=x, p(x, F x)=x, p(y, F y)=y, p(y, F x)=x /(1+x)$, $p(x, F y)=x$ and taking $\alpha=1 / 3, \beta=1 / 15, \gamma=2 / 15$, one can verify the condition of the above corollary. Thus all the conditions of Corollary 16 are satisfied and $u=0$ is a fixed point of the mapping $F$.

As an application of Theorem 9, we prove the following theorem for two finite families of mappings.

Theorem 18. If $\left\{T_{i}\right\}_{1}^{m}$ and $\left\{S_{i}\right\}_{1}^{n}$ are two pairwise commuting finite families of self-mapping defined on a complete partial metric space $(X, p)$ such that the mappings $S$ and $T$ (with $T=T_{1} T_{2} \cdots T_{m}$ and $S=S_{1} S_{2} \cdots S_{n}$ ) satisfy the contractive condition (5), then the component maps of the two families $\left\{T_{i}\right\}_{1}^{m}$ and $\left\{S_{i}\right\}_{1}^{n}$ have a unique common fixed point.

Proof. From Theorem 9, we can say that the mappings $T$ and $S$ have a unique common fixed point $z$; that is, $T z=S z=z$. Now our requirement is to show that $z$ is a common fixed point of all the component mappings of both the families. In view of pairwise commutativity of the families $\left\{T_{i}\right\}_{1}^{m}$ and $\left\{S_{i}\right\}_{1}^{n}$, (for every $1 \leq k \leq m$ ) we can write $T_{k} z=T_{k} T z=T T_{k} z$ and $T_{k} z=T_{k} S z=S T_{k} z$ which show that $T_{k} z$ (for every $k$ ) is also a common fixed point of $T$ and $S$. By using the uniqueness of common fixed point, we can write $T_{k} z=z$ (for every $k$ ) which shows that $z$ is a common fixed point of the family $\left\{T_{i}\right\}_{1}^{m}$. Using the same argument one can also show that (for every $1 \leq k \leq n) S_{k} z=z$. Thus component maps of the two families $\left\{T_{i}\right\}_{1}^{m}$ and $\left\{S_{i}\right\}_{1}^{n}$ have a unique common fixed point.

By setting $T_{1}=T_{2}=\cdots=T_{m}=F$ and $S_{1}=S_{2}=\cdots=$ $S_{n}=G$, in Theorem 18, we get the following corollary.

Corollary 19. Let $F, G: X \rightarrow X$ be two commuting selfmappings defined on a complete PMS $(X, p)$ satisfying the condition

$$
\begin{aligned}
p\left(F^{m} x, G^{n} y\right) & \\
\leq & \alpha p(x, y) \\
& +\frac{\beta p\left(x, F^{m} x\right) p\left(y, G^{n} y\right)+\gamma p\left(y, F^{m} x\right) p\left(x, G^{n} y\right)}{1+p(x, y)}
\end{aligned}
$$


for all $x, y \in X, \alpha+\beta+2 \gamma<1(\alpha, \beta$, and $\gamma$ are nonnegative reals). Then $F$ and $G$ have a unique common fixed point.

By setting $m=n$ and $F=G=T$ in Corollary 19, we deduce the following corollary.

Corollary 20. Let $T: X \rightarrow X$ be a mapping defined on a complete PMS $(X, p)$ satisfying the condition

$$
\begin{aligned}
p\left(T^{n} x, T^{n} y\right) & \\
\leq & \alpha p(x, y) \\
& +\frac{\beta p\left(x, T^{n} x\right) p\left(y, T^{n} y\right)+\gamma p\left(y, T^{n} x\right) p\left(x, T^{n} y\right)}{1+p(x, y)}
\end{aligned}
$$

for all $x, y \in X, \alpha+\beta+2 \gamma<1(\alpha, \beta$, and $\gamma$ are nonnegative reals). Then $F$ has a unique fixed point.

By setting $\beta=\gamma=0$, we draw following corollary which can be viewed as an extension of Bryant's theorem [15] for a mapping on a complete PMS $(X, p)$.

Corollary 21. Let $F: X \rightarrow X$ be a mapping on a complete PMS $(X, p)$. If $F$ satisfies

$$
p\left(F^{n} x, F^{n} y\right) \leq \alpha p(x, y)
$$

for all $x, y \in X, \alpha<1$. Then $F$ has a unique fixed point.

The following example demonstrates the superiority of Bryant's theorem over Matthews theorem on complete partial metric space.

Example 22. Let $X=[0,4]$. Define the partial metric $p: X \times$ $X \rightarrow \mathbb{R}$ by

$$
p(x, y)=\max \{x, y\} .
$$

Then $(X, p)$ is a complete partial metric space. Let $F: X \rightarrow$ $X$ be defined as follows:

$$
F(x)= \begin{cases}x^{2} & \text { if } x \in[0,1[ \\ 2 & \text { if } x \in[1,2[ \\ 0 & \text { if } x \in[2,4]\end{cases}
$$

Then for $x=0$ and $y=1$, we get

$$
p(F(0), F(1))=p(0,2)=2>\alpha p(0,1)=\alpha(1),
$$

because $0 \leq \alpha<1$. However, $F^{2}$ satisfies the requirement of Bryant's theorem and $z=0$ is the unique fixed point of $F$.

\section{Results for Set Valued Mappings}

Theorem 23. Let $(X, p)$ be a complete partial metric space and let $S, T: X \rightarrow C B^{p}(X)$ be mappings such that

$$
\begin{aligned}
H_{p}(S x, T y) \leq & \alpha p(x, y) \\
& +\frac{\beta p(x, S x) p(y, T y)+\gamma p(y, S x) p(x, T y)}{1+p(x, y)}
\end{aligned}
$$

for all $x, y \in X, 0 \leq \alpha, \beta, \gamma$ with $\alpha+\beta+2 \gamma<1$. Then $S$ and $T$ have a common fixed point.

Proof. Assume that $M=((\alpha+\gamma) /(1-\beta-\gamma))$. Let $x_{0} \in X$ be arbitrary but fixed element of $X$ and choose $x_{1} \in S\left(x_{0}\right)$. By Lemma 8 we can choose $x_{2} \in T\left(x_{1}\right)$ such that

$$
\begin{aligned}
p\left(x_{1}, x_{2}\right) \leq & H_{p}\left(S\left(x_{0}\right), T\left(x_{1}\right)\right)+(\alpha+\gamma) \\
\leq & \alpha p\left(x_{0}, x_{1}\right)+\beta \frac{p\left(x_{0}, S x_{0}\right) p\left(x_{1}, T x_{1}\right)}{1+p\left(x_{0}, x_{1}\right)} \\
& +\gamma \frac{p\left(x_{1}, S x_{0}\right) p\left(x_{0}, T x_{1}\right)}{1+p\left(x_{0}, x_{1}\right)}+(\alpha+\gamma) \\
\leq & \alpha p\left(x_{0}, x_{1}\right)+\beta \frac{p\left(x_{0}, x_{1}\right) p\left(x_{1}, x_{2}\right)}{1+p\left(x_{0}, x_{1}\right)} \\
& +\gamma \frac{p\left(x_{1}, x_{1}\right) p\left(x_{0}, x_{2}\right)}{1+p\left(x_{0}, x_{1}\right)}+(\alpha+\gamma) \\
\leq & \alpha p\left(x_{0}, x_{1}\right)+\beta \frac{p\left(x_{0}, x_{1}\right) p\left(x_{1}, x_{2}\right)}{1+p\left(x_{0}, x_{1}\right)} \\
& +\gamma \frac{p\left(x_{0}, x_{1}\right) p\left(x_{0}, x_{2}\right)}{1+p\left(x_{0}, x_{1}\right)}+(\alpha+\gamma) \\
\leq & \alpha p\left(x_{0}, x_{1}\right)+\beta p\left(x_{1}, x_{2}\right)+\gamma p\left(x_{0}, x_{2}\right) \\
& +(\alpha+\gamma) .
\end{aligned}
$$

So we get

$$
p\left(x_{1}, x_{2}\right) \leq\left(\frac{\alpha+\gamma}{1-\beta-\gamma}\right) p\left(x_{0}, x_{1}\right)+\left(\frac{\alpha+\gamma}{1-\beta-\gamma}\right) \text {. }
$$

Since $M=((\alpha+\gamma) /(1-\beta-\gamma))$, so it further implies that

$$
p\left(x_{1}, x_{2}\right) \leq M p\left(x_{0}, x_{1}\right)+M \text {. }
$$

By Lemma 8 we can choose $x_{3} \in S\left(x_{2}\right)$ such that

$$
\begin{aligned}
p\left(x_{2}, x_{3}\right) \leq & H_{p}\left(T\left(x_{1}\right), S\left(x_{2}\right)\right)+\frac{(\alpha+\gamma)^{2}}{1-\beta-\gamma} \\
\leq & \alpha p\left(x_{1}, x_{2}\right)+\beta \frac{p\left(x_{1}, T x_{1}\right) p\left(x_{2}, S x_{2}\right)}{1+p\left(x_{1}, x_{2}\right)} \\
& +\gamma \frac{p\left(x_{2}, T x_{1}\right) p\left(x_{1}, S x_{2}\right)}{1+p\left(x_{1}, x_{2}\right)}+\frac{(\alpha+\gamma)^{2}}{1-\beta-\gamma} \\
\leq & \alpha p\left(x_{1}, x_{2}\right)+\beta \frac{p\left(x_{1}, x_{2}\right) p\left(x_{2}, x_{3}\right)}{1+p\left(x_{1}, x_{2}\right)} \\
& +\gamma \frac{p\left(x_{2}, x_{2}\right) p\left(x_{1}, x_{3}\right)}{1+p\left(x_{1}, x_{2}\right)}+\frac{(\alpha+\gamma)^{2}}{1-\beta-\gamma} \\
\leq & \alpha p\left(x_{1}, x_{2}\right)+\beta \frac{p\left(x_{1}, x_{2}\right) p\left(x_{2}, x_{3}\right)}{1+p\left(x_{1}, x_{2}\right)} \\
& +\gamma \frac{p\left(x_{1}, x_{2}\right) p\left(x_{1}, x_{3}\right)}{1+p\left(x_{1}, x_{2}\right)}+\frac{(\alpha+\gamma)^{2}}{1-\beta-\gamma}
\end{aligned}
$$




$$
\begin{aligned}
\leq & \alpha p\left(x_{1}, x_{2}\right)+\beta \frac{p\left(x_{1}, x_{2}\right) p\left(x_{2}, x_{3}\right)}{1+p\left(x_{1}, x_{2}\right)} \\
& +\gamma \frac{p\left(x_{1}, x_{2}\right) p\left(x_{1}, x_{3}\right)}{1+p\left(x_{1}, x_{2}\right)}+\frac{(\alpha+\gamma)^{2}}{1-\beta-\gamma} \\
\leq & \alpha p\left(x_{1}, x_{2}\right)+\beta p\left(x_{2}, x_{3}\right)+\gamma p\left(x_{1}, x_{3}\right) \\
& +\frac{(\alpha+\gamma)^{2}}{1-\beta-\gamma} .
\end{aligned}
$$

So we get

$$
p\left(x_{2}, x_{3}\right) \leq\left(\frac{\alpha+\gamma}{1-\beta-\gamma}\right)^{2} p\left(x_{0}, x_{1}\right)+2\left(\frac{\alpha+\gamma}{1-\beta-\gamma}\right)^{2} .
$$

Continuing in this manner, one can obtain a sequence $\left\{x_{n}\right\}$ in $X$ as $x_{2 n+1} \in S\left(x_{2 n}\right)$ and $x_{2 n+2} \in T\left(x_{2 n+1}\right)$ such that

$$
\begin{aligned}
p\left(x_{n}, x_{n+1}\right) & \leq M p\left(x_{n-1}, x_{n}\right)+M \\
& \leq \cdots \leq M^{n} p\left(x_{0}, x_{1}\right)+n M^{n},
\end{aligned}
$$

where $M=((\alpha+\beta) /(1-\alpha))<1$ for all $n \geq 0$. Without loss of generality assume that $n>m$. Then, using (48) and the triangle inequality for partial metrics $\left(\mathrm{P}_{4}\right)$, we have

$$
\begin{aligned}
& p\left(x_{n}, x_{m}\right) \\
& \leq p\left(x_{n}, x_{n+1}\right)+p\left(x_{n+1}, x_{n+2}\right)+\cdots+p\left(x_{m-1}, x_{m}\right) \\
& \leq M^{n} p\left(x_{0}, x_{1}\right)+n M^{n}+M^{n+1} p\left(x_{0}, x_{1}\right) \\
& \quad+(n+1) M^{n+1}+\cdots+M^{m-1} p\left(x_{0}, x_{1}\right) \\
& \quad+(m-1) M^{m-1} \leq \sum_{i=n}^{m-1} M^{i} p\left(x_{0}, x_{1}\right) \\
& \left.\quad+\sum_{i=n}^{m-1} i M^{i} \longrightarrow 0 \text { as } n \longrightarrow+\infty \text { (since } 0<M<1\right) .
\end{aligned}
$$

By the definition of $p^{s}$, we get,

$$
p^{s}\left(x_{n}, x_{m}\right) \leq 2 p\left(x_{n}, x_{m}\right) \longrightarrow 0 \text { as } n \longrightarrow+\infty .
$$

This yields that $\left\{x_{n}\right\}$ is a Cauchy sequence in $\left(X, p^{s}\right)$. Since $(X, p)$ is complete, then from Lemma $2(4),\left(X, p^{s}\right)$ is a complete metric space. Therefore, the sequence $\left\{x_{n}\right\}$ converges to some $x^{*} \in X$ with respect to the metric $p^{s}$; that is, $\lim _{n \rightarrow+\infty} p^{s}\left(x_{n}, x^{*}\right)=0$. Again, from Lemma 2(4), we get

$$
\begin{aligned}
p\left(x^{*}, x^{*}\right)= & \lim _{n \rightarrow+\infty} p\left(x_{n}, x^{*}\right)=\lim _{n \rightarrow+\infty} p\left(x_{n}, x_{n}\right)=0, \\
H_{p}( & \left.T\left(x_{2 n+2}\right), S\left(x^{*}\right)\right) \\
\leq & \alpha p\left(x_{2 n+2}, x^{*}\right) \\
& +\beta \frac{p\left(x_{2 n+2}, T\left(x_{2 n+2}\right)\right) p\left(x^{*}, S\left(x^{*}\right)\right)}{1+p\left(x_{2 n+2}, x^{*}\right)} \\
& +\gamma \frac{p\left(x_{2 n+2}, S\left(x^{*}\right)\right) p\left(x^{*}, T\left(x_{2 n+2}\right)\right)}{1+p\left(x_{2 n+2}, x^{*}\right)} \\
\leq & \alpha p\left(x_{2 n+2}, x^{*}\right) \\
& +\beta \frac{p\left(x_{2 n+2}, x_{2 n+3}\right) p\left(x^{*}, S\left(x^{*}\right)\right)}{1+p\left(x_{2 n+2}, x^{*}\right)} \\
& +\gamma \frac{p\left(x_{2 n+2}, S\left(x^{*}\right)\right) p\left(x^{*}, x_{2 n+1}\right)}{1+p\left(x_{2 n+2}, x^{*}\right)},
\end{aligned}
$$

taking limit as $n \rightarrow \infty$ and using (51), we get

$$
\lim _{n \rightarrow+\infty} H_{p}\left(T\left(x_{2 n+2}\right), S\left(x^{*}\right)\right)=0 .
$$

Now $x_{2 n+1} \in T\left(x_{2 n+2}\right)$ gives that

$$
p\left(x_{2 n+1}, S\left(x^{*}\right)\right) \leq H_{p}\left(T\left(x_{2 n+2}\right), S\left(x^{*}\right)\right),
$$

which implies that

$$
\lim _{n \rightarrow+\infty} p\left(x_{2 n+1}, S\left(x^{*}\right)\right)=0 .
$$

On the other hand by $\left(\mathrm{P}_{4}\right)$, we have

$$
\begin{aligned}
p\left(x^{*}, S\left(x^{*}\right)\right) \leq & p\left(x^{*}, x_{2 n+2}\right)+p\left(x_{2 n+2}, S\left(x^{*}\right)\right) \\
& -p\left(x_{2 n+2}, x_{2 n+2}\right) \\
\leq & p\left(x^{*}, x_{2 n+2}\right)+p\left(x_{2 n+2}, S\left(x^{*}\right)\right) .
\end{aligned}
$$

Taking limit as $n \rightarrow+\infty$ and using (51) and (55), we obtain $p\left(x^{*}, S\left(x^{*}\right)\right)=0$. Therefore, from (51) $\left(p\left(x^{*}, x^{*}\right)=0\right)$, we obtain

$$
p\left(x^{*}, S\left(x^{*}\right)\right)=p\left(x^{*}, x^{*}\right)
$$

which from Remark 14 implies that $x^{*} \in \overline{S\left(x^{*}\right)}=S\left(x^{*}\right)$. Similarly one can easily prove that $x^{*} \in T\left(x^{*}\right)$. Thus $S$ and $T$ have a common fixed point.

Remark 24. For $\beta=\gamma=0$ and $S=T$, Theorem 23 reduces to the following result of Aydi et al. [9].

Corollary 25 (see [9, Theorem 3.2]). Let $(X, p)$ be a partial metric space. If $T: X \rightarrow C B^{p}(X)$ is a multivalued mapping such that for all $x, y \in X$, one has

$$
H_{p}(T x, T y) \leq k p(a, b),
$$

where $k \in(0,1)$. Then $T$ has a fixed point. 
Theorem 26. Let $(X, p)$ be a complete partial metric space and $S, T: X \rightarrow C B^{p}(X)$ be multivalued mappings such that

$$
\begin{aligned}
H_{p}(S x, T y) \leq & \alpha\left\{\frac{p(x, S x) p(x, T y)+p(y, T y) p(y, S x)}{p(x, T y)+p(y, S x)}\right\} \\
& +\beta d(x, y)
\end{aligned}
$$

for all $x, y \in X, 0 \leq \alpha, \beta$ with $2 \alpha+\beta<1$, and $p(x, T y)+$ $p(y, S x) \neq 0$. Then $S$ and $T$ have a common fixed point.

Proof. Assume that $l=(\alpha+\beta) /(1-\alpha)$. Let $x_{0} \in X$ be arbitrary but fixed element of $X$ and choose $x_{1} \in S\left(x_{0}\right)$.

When $p(x, T y)+p(y, S x) \neq 0$. By Lemma 8 we can choose $x_{2} \in T\left(x_{1}\right)$ such that

$$
\begin{aligned}
p\left(x_{1}, x_{2}\right) & \\
\leq & H_{p}\left(S\left(x_{0}\right), T\left(x_{1}\right)\right)+(\alpha+\beta) \\
\leq & \alpha\left\{\frac{p\left(x_{0}, S x_{0}\right) p\left(x_{0}, T x_{1}\right)+p\left(x_{1}, T x_{1}\right) p\left(x_{1}, S x_{0}\right)}{p\left(x_{0}, T x_{1}\right)+p\left(x_{1}, S x_{0}\right)}\right\} \\
& +\beta p\left(x_{0}, x_{1}\right)+(\alpha+\beta) \\
\leq & \alpha\left\{\frac{p\left(x_{0}, x_{1}\right) p\left(x_{0}, x_{2}\right)+p\left(x_{1}, x_{2}\right) p\left(x_{1}, x_{1}\right)}{p\left(x_{0}, x_{2}\right)+p\left(x_{1}, x_{1}\right)}\right\} \\
& +\beta p\left(x_{0}, x_{1}\right)+(\alpha+\beta) \\
\leq & \alpha\left\{p\left(x_{0}, x_{1}\right)+p\left(x_{1}, x_{2}\right)\right\}+\beta p\left(x_{0}, x_{1}\right)+(\alpha+\beta)
\end{aligned}
$$

because $p\left(x_{0}, x_{2}\right)<p\left(x_{0}, x_{2}\right)+p\left(x_{1}, x_{1}\right)$ and $p\left(x_{1}, x_{1}\right)<$ $p\left(x_{1}, x_{1}\right)+p\left(x_{0}, x_{2}\right)$. Thus we get

$$
p\left(x_{1}, x_{2}\right) \leq\left(\frac{\alpha+\beta}{1-\alpha}\right) p\left(x_{0}, x_{1}\right)+\left(\frac{\alpha+\beta}{1-\alpha}\right) .
$$

It further implies that

$$
p\left(x_{1}, x_{2}\right) \leq l p\left(x_{0}, x_{1}\right)+l .
$$

By Lemma 8 we can choose $x_{3} \in S\left(x_{2}\right)$ such that

$$
\begin{aligned}
& p\left(x_{2}, x_{3}\right) \\
& \leq H_{p}\left(T\left(x_{1}\right), S\left(x_{2}\right)\right)+\frac{(\alpha+\beta)^{2}}{1-\alpha} \\
& \leq \alpha\left\{\frac{p\left(x_{1}, T x_{1}\right) p\left(x_{1}, S x_{2}\right)+p\left(x_{2}, S x_{2}\right) p\left(x_{2}, T x_{1}\right)}{p\left(x_{1}, S x_{2}\right)+p\left(x_{2}, T x_{1}\right)}\right\} \\
& \quad+\beta p\left(x_{1}, x_{2}\right)+\frac{(\alpha+\beta)^{2}}{1-\alpha}
\end{aligned}
$$

$$
\begin{aligned}
\leq & \alpha\left\{\frac{p\left(x_{1}, x_{2}\right) p\left(x_{1}, x_{3}\right)+p\left(x_{2}, x_{3}\right) p\left(x_{2}, x_{2}\right)}{p\left(x_{1}, x_{3}\right)+p\left(x_{2}, x_{2}\right)}\right\} \\
& +\beta p\left(x_{1}, x_{2}\right)+\frac{(\alpha+\beta)^{2}}{1-\alpha} \\
\leq & \alpha\left\{p\left(x_{1}, x_{2}\right)+p\left(x_{2}, x_{3}\right)\right\}+\beta p\left(x_{1}, x_{2}\right)+\frac{(\alpha+\beta)^{2}}{1-\alpha}
\end{aligned}
$$

because $p\left(x_{1}, x_{3}\right)<p\left(x_{1}, x_{3}\right)+p\left(x_{2}, x_{2}\right)$ and $p\left(x_{2}, x_{2}\right)<$ $p\left(x_{2}, x_{2}\right)+p\left(x_{1}, x_{3}\right)$. Thus we get

$$
p\left(x_{2}, x_{3}\right) \leq\left(\frac{\alpha+\beta}{1-\alpha}\right) p\left(x_{1}, x_{2}\right)+\left(\frac{\alpha+\beta}{1-\alpha}\right)^{2} .
$$

It further implies that

$$
p\left(x_{2}, x_{3}\right) \leq l^{2} p\left(x_{0}, x_{0}\right)+2 l^{2} .
$$

Continuing in this manner, one can obtain a sequence $\left\{x_{n}\right\}$ in $X$ as $x_{2 n+1} \in S\left(x_{2 n}\right)$ and $x_{2 n+2} \in T\left(x_{2 n+1}\right)$ such that

$$
p\left(x_{n}, x_{n+1}\right) \leq l p\left(x_{n-1}, x_{n}\right)+l \leq \cdots \leq l^{n} p\left(x_{0}, x_{1}\right)+n l^{n},
$$

where $l=((\alpha+\beta) /(1-\alpha))<1$ for all $n \geq 0$. Without loss of generality assume that $m>n$. Then using (66) and the triangle inequality for partial metrics $\left(\mathrm{P}_{4}\right)$, one can easily prove that

$$
\begin{aligned}
p\left(x_{n}, x_{m}\right) & \leq \sum_{i=n}^{m-1} l^{i} p\left(x_{0}, x_{1}\right)+\sum_{i=n}^{m-1} i l^{i} \\
& \longrightarrow 0 \text { as } n \longrightarrow+\infty(\text { since } 0<l<1) .
\end{aligned}
$$

By the definition of $p^{s}$,

$$
p^{s}\left(x_{n}, x_{m}\right) \leq 2 p\left(x_{n}, x_{m}\right) \longrightarrow 0 \text { as } n \longrightarrow+\infty .
$$

This yields that $\left\{x_{n}\right\}$ is a Cauchy sequence in $\left(X, p^{s}\right)$. Since $(X, p)$ is complete, then from Lemma $2(4),\left(X, p^{s}\right)$ is a complete metric space. Therefore, the sequence $\left\{x_{n}\right\}$ converges to some $x^{\prime} \in X$ with respect to the metric $p^{s}$; that is, $\lim _{n \rightarrow+\infty} p^{s}\left(x_{n}, x^{\prime}\right)=0$. Again, from Lemma 2(4), we get

$$
p\left(x^{\prime}, x^{\prime}\right)=\lim _{n \rightarrow+\infty} p\left(x_{n}, x^{\prime}\right)=\lim _{n \rightarrow+\infty} p\left(x_{n}, x_{n}\right)=0
$$




$$
\begin{aligned}
H_{p}( & \left.T\left(x_{2 n+1}\right), S\left(x^{\prime}\right)\right) \\
\leq \alpha\{( & p\left(x_{2 n+1}, T\left(x_{2 n+1}\right)\right) p\left(x_{2 n+1}, S\left(x^{\prime}\right)\right) \\
+ & \left.p\left(x^{\prime}, S\left(x^{\prime}\right)\right) p\left(x^{\prime}, T\left(x_{2 n+1}\right)\right)\right) \\
\times & \left.\left(p\left(x_{2 n+1}, S\left(x^{\prime}\right)\right)+p\left(x^{\prime}, T\left(x_{2 n+1}\right)\right)\right)^{-1}\right\} \\
+\beta p & \left(x_{2 n+1}, x^{\prime}\right) \\
\leq \alpha & \left\{\left(p \left(\left(x_{2 n+1}, x_{2 n+2}\right) p\left(x_{2 n+1}, S\left(x^{\prime}\right)\right)\right.\right.\right. \\
+ & \left.\left.p\left(x^{\prime}, S\left(x^{\prime}\right)\right) p\left(x^{\prime}, x_{2 n+2}\right)\right)\right) \\
\times( & \left.\left(p\left(x_{2 n+1}, S\left(x^{\prime}\right)\right)+p\left(x^{\prime}, x_{2 n+2}\right)\right)^{-1}\right\} \\
+\beta p & \left(x_{2 n+1}, x^{\prime}\right),
\end{aligned}
$$

therefore

$$
\lim _{n \rightarrow+\infty} H_{p}\left(T\left(x_{2 n+1}\right), S\left(x^{\prime}\right)\right)=0 .
$$

Now $x_{2 n+2} \in T\left(x_{2 n+1}\right)$ gives that

$$
p\left(x_{2 n+2}, S\left(x^{\prime}\right)\right) \leq H_{p}\left(T\left(x_{2 n+1}\right), S\left(x^{\prime}\right)\right)
$$

which implies that

$$
\lim _{n \rightarrow+\infty} p\left(x_{2 n+2}, S\left(x^{\prime}\right)\right)=0 .
$$

On the other hand, we have

$$
\begin{aligned}
p\left(x^{\prime}, S\left(x^{\prime}\right)\right) \leq & p\left(x^{\prime}, x_{2 n+2}\right)+p\left(x_{2 n+2}, S\left(x^{\prime}\right)\right) \\
& -p\left(x_{2 n+2}, x_{2 n+2}\right) \\
\leq & p\left(x^{\prime}, x_{2 n+2}\right)+p\left(x_{2 n+2}, S\left(x^{\prime}\right)\right) .
\end{aligned}
$$

Taking limit as $n \rightarrow+\infty$ and using (69) and (73), we obtain $p\left(x^{\prime}, S\left(x^{\prime}\right)\right)=0$. Therefore, from $(69)\left(p\left(x^{\prime}, x^{\prime}\right)=0\right)$, we obtain

$$
p\left(x^{\prime}, S\left(x^{\prime}\right)\right)=p\left(x^{\prime}, x^{\prime}\right)
$$

which from Remark 14 implies that $x^{\prime} \in \overline{S\left(x^{\prime}\right)}=S\left(x^{\prime}\right)$. It follows similarly that $x^{\prime} \in T\left(x^{\prime}\right)$. Thus $S$ and $T$ have a common fixed point.

Now we give an example which illustrates our Theorem 26.
Example 27. Let $X=\{1,2,3\}$ be endowed with usual order and let $p$ be a partial metric on $X$ defined as

$$
\begin{aligned}
& p(1,1)=p(2,2)=0, \quad p(3,3)=\frac{5}{11}, \\
& p(1,2)=p(2,1)=\frac{3}{10}, \\
& p(1,3)=p(3,1)=\frac{9}{20}, \\
& p(2,3)=p(3,2)=\frac{1}{2} .
\end{aligned}
$$

Define the mappings $S, T: X \rightarrow C B_{p}(X)$ by

$$
\begin{gathered}
S x= \begin{cases}\{1\} & \text { if } x, y \in\{1,2\} \\
\{1,2\} & \text { otherwise }\end{cases} \\
T x= \begin{cases}\{1\} & \text { if } x, y \in\{1,2\} \\
\{2\} & \text { otherwise. }\end{cases}
\end{gathered}
$$

Note that $S x$ and $T x$ are closed and bounded for all $x \in X$ with respect to the partial metric $p$. To show that for all $x, y$ in $X$, (59) is satisfied with $\alpha=1 / 11, \beta=4 / 5$, we consider the following cases: if $x, y \in\{1,2\}$, then,

$$
H_{p}(S x, T y)=H_{p}(\{1\},\{1\})=0
$$

and condition (59) is satisfied obviously.

$$
\text { If } x=y=3 \text {, then }
$$

$$
\begin{gathered}
H_{p}(S x, T y)=H_{p}(\{1,2\},\{2\})=\frac{3}{10}, \\
p(x, S x)=p(y, S x)=p(3,\{1,2\})=\frac{9}{20}, \\
p(x, T y)=p(y, T y)=p(y, S x)=p(3,\{2\})=\frac{11}{24}, \\
p(x, y)=p(3,3)=\frac{5}{11} .
\end{gathered}
$$$$
\text { If } x=3, y=1 \text {, then }
$$

$$
H_{p}(S x, T y)=H_{p}(\{1,2\},\{1\})=\frac{3}{10},
$$

$$
\begin{gathered}
p(x, S x)=p(3,\{1,2\})=\frac{9}{20}, \quad p(x, T y)=p(3,\{1\})=\frac{9}{20}, \\
p(y, T y)=p(1,\{1\})=0, \quad p(y, S x)=p(1,\{1,2\})=0, \\
p(x, y)=p(3,1)=\frac{9}{20} .
\end{gathered}
$$


If $x=3, y=2$, then

$$
\begin{gathered}
H_{p}(S x, T y)=H_{p}(\{1,2\},\{1\})=\frac{3}{10}, \\
p(x, S x)=p(3,\{1,2\})=\frac{9}{20}, \quad p(x, T y)=p(3,\{1\})=\frac{9}{20}, \\
p(y, T y)=p(2,\{1\})=\frac{3}{10}, \quad p(y, S x)=p(2,\{1,2\})=0, \\
p(x, y)=p(3,2)=\frac{1}{2} .
\end{gathered}
$$

If $x=1, y=3$, then

$$
\begin{gathered}
H_{p}(S x, T y)=H_{p}(\{1\},\{2\})=\frac{3}{10}, \\
p(x, S x)=p(1,\{1\})=0, \quad p(x, T y)=p(1,\{2\})=\frac{3}{10}, \\
p(y, T y)=p(3,\{2\})=\frac{1}{2}, \quad p(y, S x)=p(3,\{1\})=\frac{9}{20}, \\
p(x, y)=p(1,3)=\frac{9}{20} .
\end{gathered}
$$

If $x=2, y=3$, then

$$
\begin{gathered}
H_{p}(S x, T y)=H_{p}(\{1\},\{2\})=\frac{3}{10}, \\
p(x, S x)=p(2,\{1\})=\frac{3}{10}, \quad p(x, T y)=p(2,\{2\})=0, \\
p(y, T y)=p(3,\{2\})=\frac{1}{2}, \quad p(y, S x)=p(3,\{1\})=\frac{9}{20}, \\
p(x, y)=p(2,3)=\frac{1}{2} .
\end{gathered}
$$

Thus, all the conditions of Theorem 26 are satisfied. Here $x=$ 1 is a common fixed point of $S$ and $T$.

On the other hand, the metric $p^{s}$ induced by the partial metric $p$ is given by

$$
\begin{gathered}
p^{s}(1,1)=p^{s}(2,2)=p^{s}(3,3)=0, \\
p^{s}(2,1)=p^{s}(2,1)=\frac{3}{4}, \\
p^{s}(3,2)=p^{s}(2,3)=\frac{4}{7}, \\
p^{s}(3,1)=p^{s}(1,3)=\frac{14}{29} .
\end{gathered}
$$

Note that in case of ordinary Hausdorff metric, given mapping does not satisfy the condition. Indeed, for $x=1$ and $y=3$, we have

$$
\begin{gathered}
H(S x, T y)=H(\{1\},\{2\})=\frac{3}{4}, \\
p^{s}(x, S x)=p^{s}(1,\{1\})=0, \\
p^{s}(x, T y)=p^{s}(1,\{2\})=\frac{3}{4}, \\
p^{s}(y, T y)=p^{s}(3,\{2\})=\frac{4}{7}, \\
p^{s}(y, S x)=p^{s}(3,\{1\})=\frac{14}{29},
\end{gathered}
$$

for the values of $\alpha=1 / 11, \beta=4 / 5$. By a routine calculation one can easily verify that the mapping does not satisfy the condition which involved ordinary Hausdorff metric.

\section{Acknowledgment}

This paper was funded by the Deanship of Scientific Research (DSR), King Abdulaziz University, Jeddah. The authors, therefore, acknowledge with thanks DSR technical and financial support.

\section{References}

[1] S. G. Matthews, "Partial metric topology," in Proceedings of the 8th Summer Conference on General Topology and Applications, vol. 728, pp. 183-197, New York Academy of Science, 1994.

[2] T. Abdeljawad, E. Karapinar, and K. Tas, "A generalized contraction principle with control functions on partial metric spaces," Computers \& Mathematics with Applications, vol. 63, no. 3, pp. 716-719, 2012.

[3] T. Abdeljawad, "Fixed points for generalized weakly contractive mappings in partial metric spaces," Mathematical and Computer Modelling, vol. 54, no. 11-12, pp. 2923-2927, 2011.

[4] J. Ahmad, M. Arshad, and C. Vetro, "On a theorem of Khan in a generalized metric space," International Journal of Analysis, vol. 2013, Article ID 852727, 6 pages, 2013.

[5] S. Alsulami, N. Hussain, and A. Alotaibi, "Coupled fixed and coincidence points for monotone operators in partial metric spaces," Fixed Point Theory and Applications, vol. 2012, article 173, 2012.

[6] I. Altun and A. Erduran, "Fixed point theorems for monotone mappings on partial metric spaces," Fixed Point Theory and Applications, vol. 2011, Article ID 508730, 2011.

[7] M. Arshad, J. Ahmad, and E. Karapinar, "Some common fixed point results in rectangular metric spaces," International Journal of Analysis, vol. 2013, Article ID 307234, 7 pages, 2013.

[8] M. Arshad, E. Karapinar, and J. Ahmad, "Some unique fixed point theorem for rational contractions in partially ordered metric spaces," Journal of Inequalities and Applications, vol. 2013, article 248, 2013.

[9] H. Aydi, M. Abbas, and C. Vetro, "Partial Hausdorff metric and Nadler's fixed point theorem on partial metric spaces," Topology and Its Applications, vol. 159, no. 14, pp. 3234-3242, 2012. 
[10] H. Aydi, M. Abbas, and C. Vetro, "Common Fixed points for multivalued generalized contractions on partial metric spaces," Revista de la Real Academia de Ciencias Exactas, Fisicas y Naturales A, 2013.

[11] A. Azam and M. Arshad, "Fixed points of a sequence of locally contractive multivalued maps," Computers \& Mathematics with Applications, vol. 57, no. 1, pp. 96-100, 2009.

[12] A. Azam, B. Fisher, and M. Khan, "Common fixed point theorems in complex valued metric spaces," Numerical Functional Analysis and Optimization, vol. 32, no. 3, pp. 243-253, 2011.

[13] S. Banach, "Sur les opérations dans les ensembles abstraits et leurs applications aux équations intégrales," Fundamenta Mathematicae, vol. 3, pp. 133-181, 1922.

[14] I. Beg and A. Azam, "Fixed points of asymptotically regular multivalued mappings," Journal of the Australian Mathematical Society A, vol. 53, no. 3, pp. 313-326, 1992.

[15] V. W. Bryant, "A remark on a fixed-point theorem for iterated mappings," The American Mathematical Monthly, vol. 75, pp. 399-400, 1968.

[16] K. P. Chi, E. Karapınar, and T. D. Thanh, "A generalized contraction principle in partial metric spaces," Mathematical and Computer Modelling, vol. 55, no. 5-6, pp. 1673-1681, 2012.

[17] N. Hussain, H. K. Nashine, Z. Kadelburg, and S. M. Alsulami, "Weakly isotone increasing mappings and endpoints in partially ordered metric spaces," Journal of Inequalities and Applications, vol. 2012, article 232, 2012.

[18] N. Hussain, D. DJorić, Z. Kadelburg, and S. Radenović, "Suzukitype fixed point results in metric type spaces," Fixed Point Theory and Applications, vol. 2012, article 126, 2012.

[19] N. Hussain, Z. Kadelburg, S. Radenovic, and F. R. Al-Solamy, "Comparison functions and fixed point results in partial metric spaces," Abstract and Applied Analysis, vol. 2012, Article ID 605781, 15 pages, 2012.

[20] N. Hussain and M. Abbas, "Common fixed point results for two new classes of hybrid pairs in symmetric spaces," Applied Mathematics and Computation, vol. 218, no. 2, pp. 542-547, 2011.

[21] S. Hong, "Fixed points of multivalued operators in ordered metric spaces with applications," Nonlinear Analysis. Theory, Methods \& Applications, vol. 72, no. 11, pp. 3929-3942, 2010.

[22] S. Hong, "Fixed points for mixed monotone multivalued operators in Banach spaces with applications," Journal of Mathematical Analysis and Applications, vol. 337, no. 1, pp. 333-342, 2008.

[23] S. Hong, "Fixed points of discontinuous multivalued increasing operators in Banach spaces with applications," Journal of Mathematical Analysis and Applications, vol. 282, no. 1, pp. 151-162, 2003.

[24] M. Imdad, J. Ali, and M. Tanveer, "Coincidence and common fixed point theorems for nonlinear contractions in Menger PM spaces," Chaos, Solitons \& Fractals, vol. 42, no. 5, pp. 3121-3129, 2009.

[25] E. Karapinar, "Ciric type nonunique fixed point theorems on partial metric spaces," The Journal of Nonlinear Science and Applications, vol. 5, no. 2, pp. 74-83, 2012.

[26] E. Karapnar and I. M. Erhan, "Fixed point theorems for operators on partial metric spaces," Applied Mathematics Letters, vol. 24, no. 11, pp. 1894-1899, 2011.

[27] E. Karapinar, M. Marudai, and V. Pragadeeshwarar, "Fixed point theorems for generalized weak contractions satisfying rational expressions on ordered Partial Metric Space," Lobachevskii Journal of Mathematics, vol. 34, no. 1, pp. 116-123, 2013.

[28] M. S. Khan, M. Swaleh, and M. Imdad, Some Fixed Point Theorems IV, Communications, 1983. 


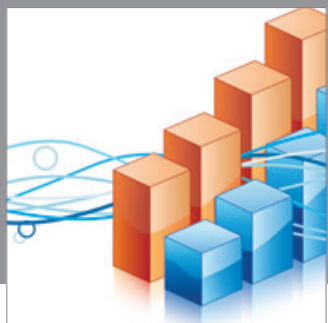

Advances in

Operations Research

mansans

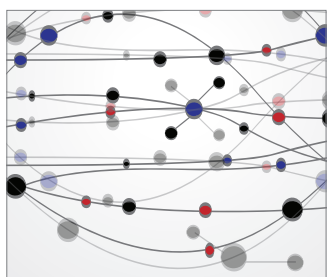

The Scientific World Journal
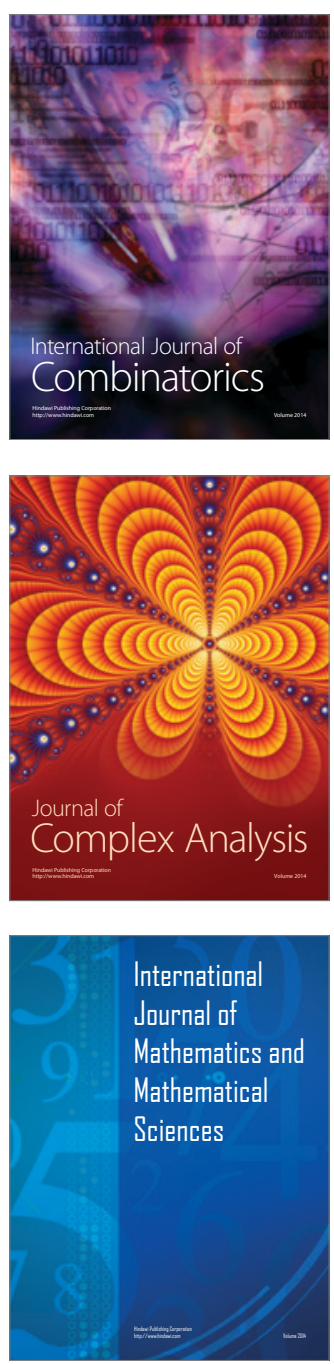
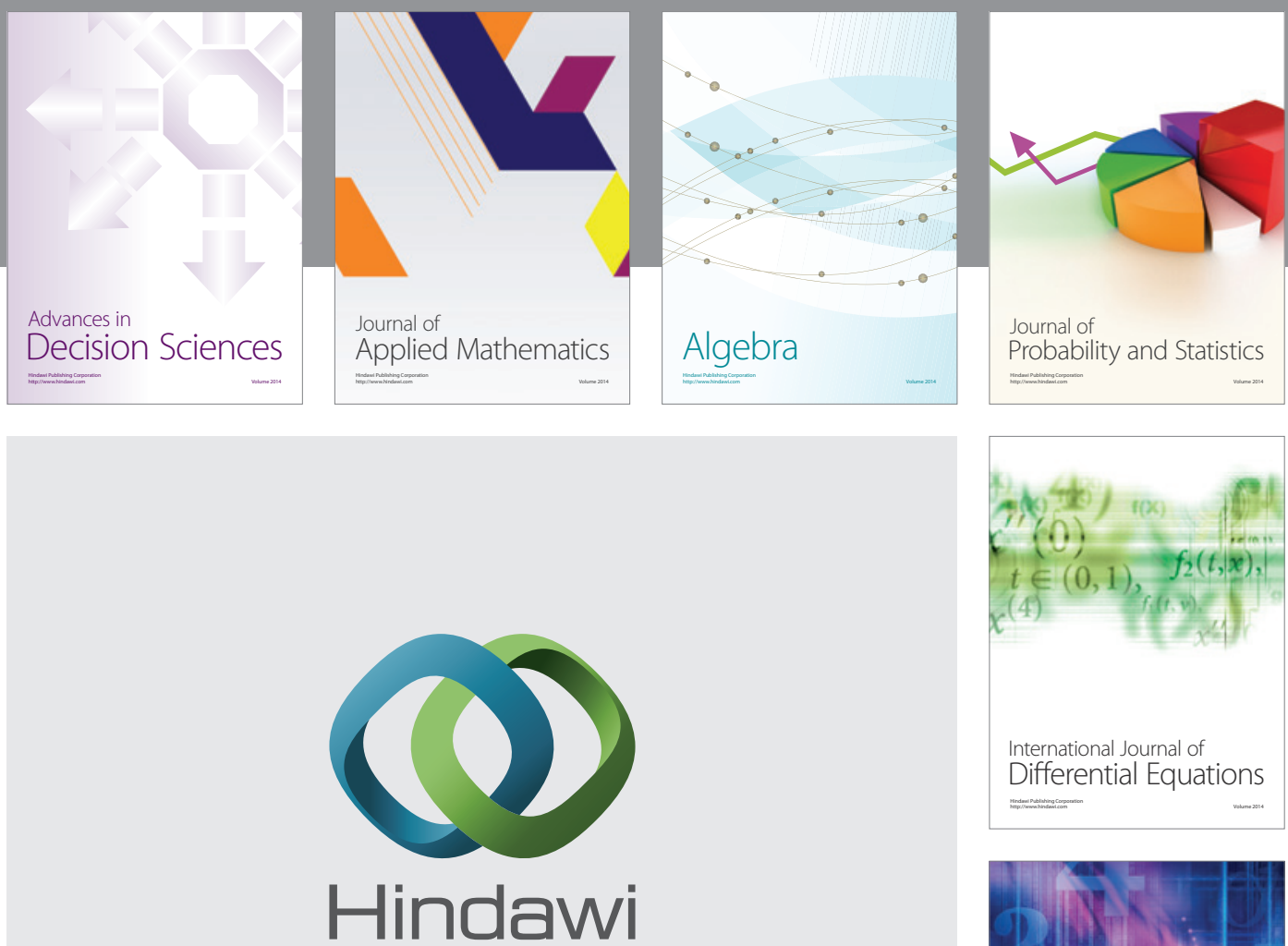

Submit your manuscripts at http://www.hindawi.com
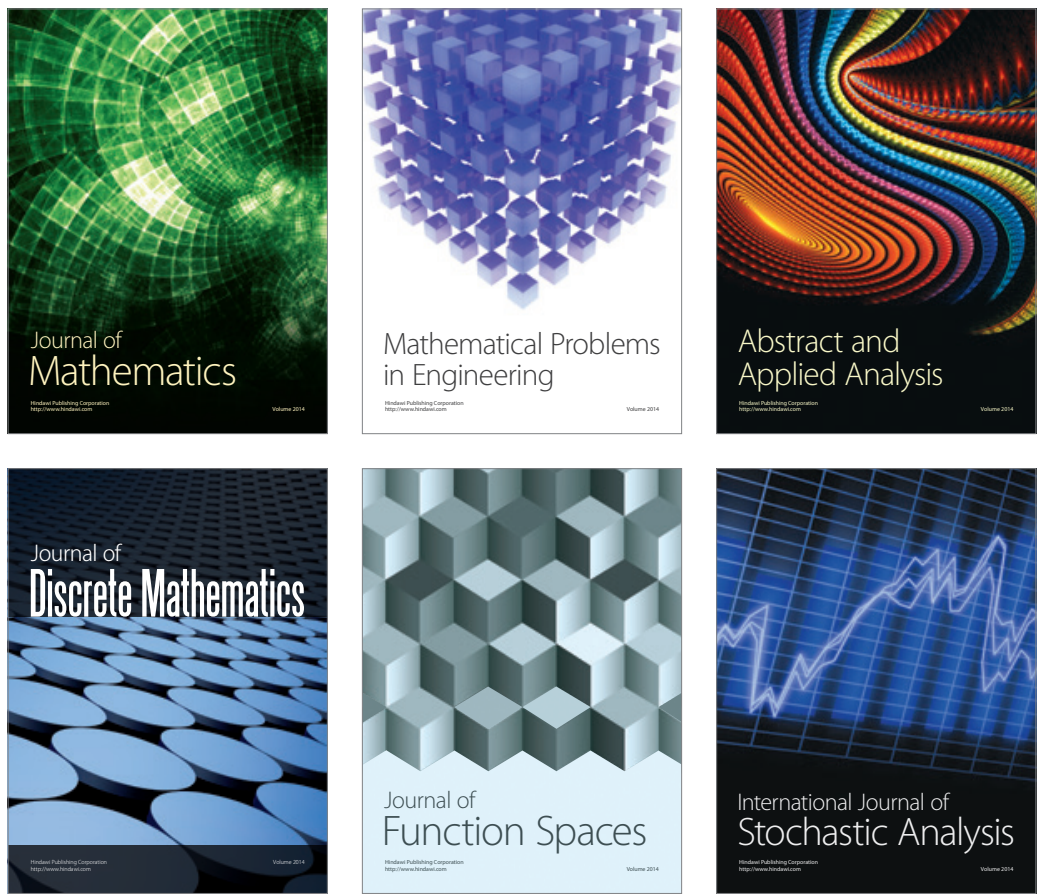

Journal of

Function Spaces

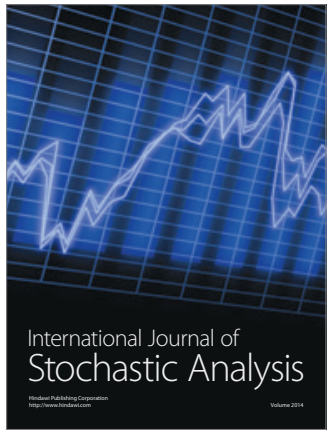

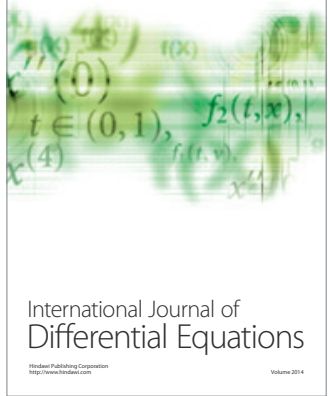
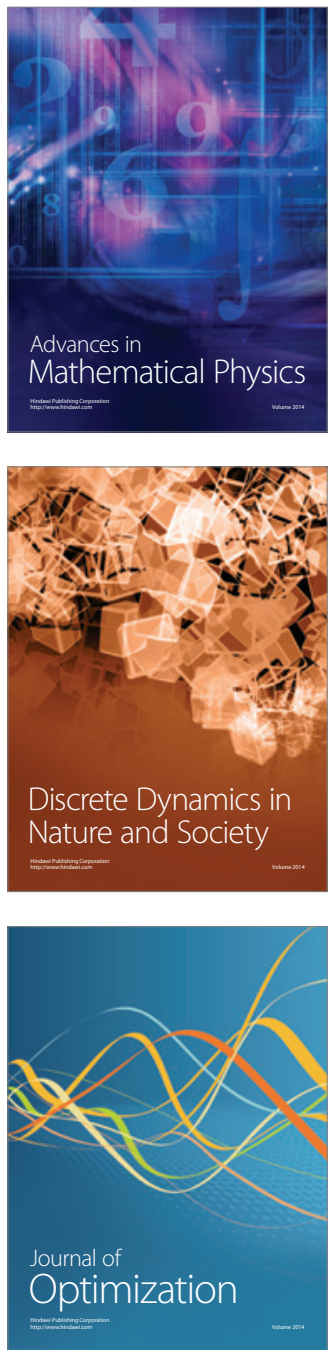